\title{
Debanding and repair of ventricular septal defect: a new technique for older patients
}

\author{
P LAURIDSEN, A UHRENHOLDT, AND I H RYGG \\ From the Department of Thoracic Surgery $R$ and Cardiovascular Laboratory of Medical \\ Department B Rigshospitalet, Copenhagen, Denmark
}

ABSTRACT Between October 1972 and April 197715 patients underwent definitive repair of a ventricular septal defect (VSD) and reconstruction of the pulmonary artery at the banding site. This report presents pre- and post-operative haemodynamic data in 12 patients, seven to 22 years after banding (mean 13.4).

Banding of the pulmonary artery was performed before the age of 6 months (mean 4). The indications were increased pulmonary blood flow and intractable heart failure. As we had previously become dissatisfied with patch angioplasty of the main pulmonary artery, we introduced a new technique in this group of excising the site of the band and anastomosing the pulmonary artery end-to-end. The gradient between the right ventricle and pulmonary artery was abolished completely in nine cases and reduced to below $30 \mathrm{mmHg}$ in the remaining three patients.

This technique is used only in older patients in whom the banding has persisted for a long time. In children under 2 years of age we usually remove the band and dilate the pulmonary artery.

The beneficial effects of banding of the pulmonary artery in infants with severe congestive heart failure caused by ventricular septal defect (VSD) (isolated or in combination with other cardiac anomalies) are well established (Muller and Dammann, 1952). The extensive study by Hunt et al (1971) showed a three-fold haemodynamic gain: (1) reduction in the pulmonary artery pressure; (2) reduction of excessive pulmonary blood flow; and (3) reduction of the pulmonary resistance towards normal with possible prevention of the progression of pulmonary vascular obstructive disease.

Palliative banding of the pulmonary artery is followed later by a corrective operation at which the VSD is closed and the band removed. Almost one-half of the patients in whom this is performed need a patch in the pulmonary artery to relieve a fixed stenosis at the banding site (Hunt et al, 1971) and despite this a gradient caused by the posterior crest may persist in some patients.

In the present group of patients in whom definitive repair was performed so late after the first operation very severe fibrosis was found at the banding site. Accordingly, to avoid residual stenosis after debanding we used a different tech- nique comprising resection of the banding site with end-to-end anastomosis of the main pulmonary artery and closure of the ventricular septal defect. This paper deals with the haemodynamic results.

\section{Patients}

The indications for banding of the pulmonary artery were increased pulmonary blood flow and pulmonary hypertension resulting in heart failure intractable to medical treatment (Therkelsen et al, 1959).

These infants were banded by Therkelsen at Queen Louise's Children's Hospital, Copenhagen, during the years 1955-66, where he banded in all 47 babies with VSD (Therkelsen, 1968). They were kept under observation and not referred for surgical correction until increasing cyanosis appeared. Thus we have a series of extraordinarily long observation times after banding.

The degree of banding was in every case controlled by pressure measurement, and a systolic pressure peripheral to the band of $40 \mathrm{mmHg}$ was aimed at. Despite this high degree of narrowing the patients were in excellent condition and cy- 
anosis was moderate up to the time of correction.

Between October 1972 and April 197715 patients underwent definitive repair of the VSD and reconstruction of the pulmonary artery at the banding site with the technique described below.

The table shows details of the 12 (six male, six female) patients at follow-up who were aged 8-22 years (mean 14.6). The pulmonary artery banding was performed before the age of 6 months (mean 4) in all cases.

\section{Details of the 12 patients at the time of follow-up}

\begin{tabular}{llllcl}
\hline Case & Age/sex & $\begin{array}{l}\text { Age at } \\
\text { banding (mo) }\end{array}$ & $\begin{array}{l}\text { Banding } \\
\text { period }(y r)\end{array}$ & $\begin{array}{l}\text { Observation } \\
\text { time (months) }\end{array}$ \\
\hline 1 & 11 & F & 6 & 9 & 15 \\
2 & 13 & M & 5 & 10 & 12 \\
3 & 15 & M & 2 & 14 & 10 \\
4 & 15 & F & 4 & 15 & 1 \\
5 & 14 & M & 5 & 13 & 6 \\
6 & 15 & F & 3 & 15 & 6 \\
7 & 18 & F & 4 & 15 & 28 \\
8 & 14 & F & 3 & 11 & 12 \\
9 & 15 & M & 3 & 14 & 12 \\
10 & 22 & F & 5 & 22 & 13 \\
11 & 8 & M & 3 & 7 & 12 \\
12 & 16 & M & 5 & 15 & 9 \\
Mean & $14 \cdot 6$ years & 4 months & $13 \cdot 4$ years & $11 \cdot 3$ months \\
\hline
\end{tabular}

The banding persisted for seven to 22 years (mean 13.4). Cardiac catheterisation was performed before debanding in all cases. The postoperative observation time has varied from one to 28 months (mean 11.3). There were two operative deaths, and one patient has not been recatheterised.

Twelve patients are included in the follow-up study. They underwent cardiac catheterisation before banding, before total repair, and after debanding.

\section{Operative technique}

The new technique involves excision of the banded area and an end-to-end anastomosis of the pulmonary artery (fig 1). The band was positioned on the main pulmonary artery between the pulmonary artery bifurcation and the pulmonary valve in all cases. In the same period we had four cases where the band had slipped out to the bifurcation, and a patch repair was used. In a fifth case where the band had resulted in narrowing of both branches of the pulmonary artery we proceeded with the new technique. This was an error, and led to one of the two operative deaths.

The band consisted of umbilical tape threaded through a silicone tube. There was severe fibrous reaction in the region of the band in all cases. Infundibular resection was performed in all
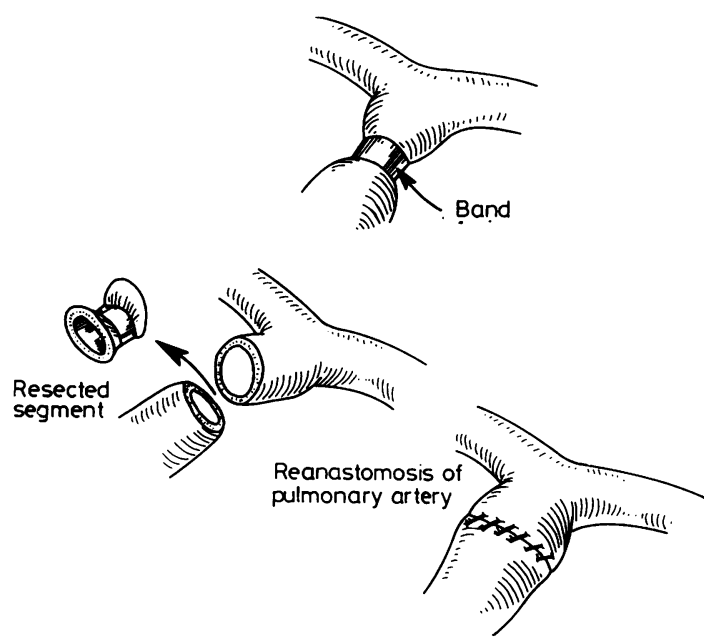

Fig 1 New technique for relieving obstruction after banding. Segment is excised and end-to-end anastomosis performed.

patients to relieve the acquired infundibular stenosis. The VSD was closed with a Dacron prosthesis.

\section{Results}

The systolic pressure in the pulmonary artery decreased from a mean value of $68 \mathrm{mmHg}$ (SD 10) before to $24 \mathrm{mmHg}$ (SD 6.9) after banding (fig 2). This is statistically significant $(\mathrm{P}<0.001)$. Debanding and VSD closure caused a slight but incon- 으 stant increase in the systolic pulmonary artery $\underset{x}{\stackrel{0}{x}}$ pressure to $27 \mathrm{mmHg}$ (SD 7:3).

The right ventricular systolic pressure showed a striking reduction from a mean value of $103 \AA$ $\mathrm{mmHg}$ (SD 1.5) before to a mean value of $36 ₹$ $\mathrm{mmHg}$ (SD 10.4) after debanding ( $<<0.001)$ (fig 3$)$. 옥 Complete normalisation was obtained in only $>$ seven patients as five patients still had values between 45 and $55 \mathrm{mmHg}$. There was no significant $N$ change in the mean right ventricular pressure before and after debanding.

The pressure gradient across the pulmonary band varied between 42 and $105 \mathrm{mmHg}$ (mean $80 \mathrm{mmHg}$ (SD 16.8)) and after debanding the mean was 8.4 mmHg (SD 8.6) (fig 4).

Before banding four patients had varying de- $\stackrel{\oplus}{+}$ grees of left to right shunt (fig 5). After the $\underset{T}{0}$ second operation the VSD was completely closed $\stackrel{\vec{\Phi}}{\vec{D}}$ in nine patients while minor left to right shunts $\stackrel{\mathbb{Q}}{\mathbb{Q}}$ remained in three. Debanding caused the heart to $\stackrel{\mathbb{Q}}{\stackrel{2}{ }}$ increase slightly in size from a mean value of $\bar{\sigma}$ $412 \mathrm{ml} /{ }^{2}$ body surface area (Jonsell, 1939) (SD 73.9 ) to $443 \mathrm{ml} /{ }^{2}$ body surface area (SD 68). The 
patient with the largest heart had tricuspid incompetence and a small residual VSD after the operation. This patient also had the highest enddiastolic pressure in the right ventricle (fig 6).

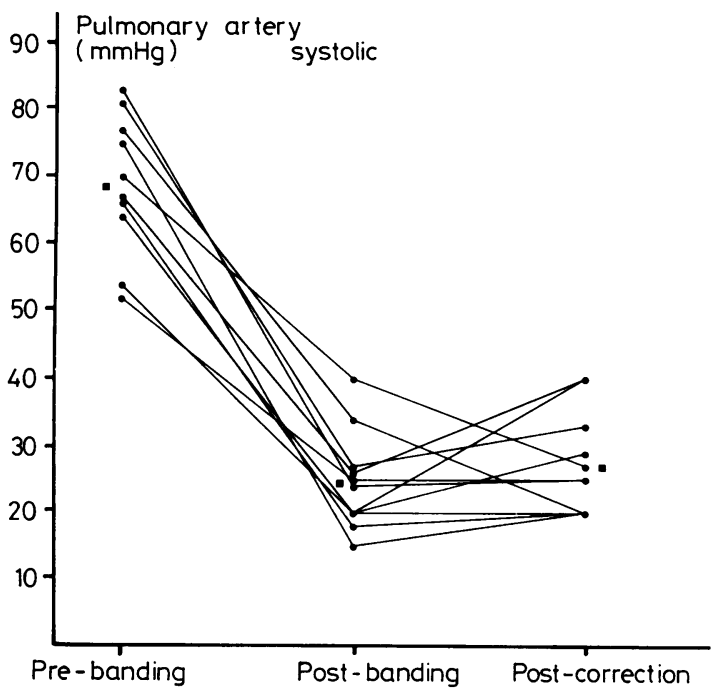

Fig 2 Pulmonary artery systolic pressure before banding, after banding, and after definitive repair.

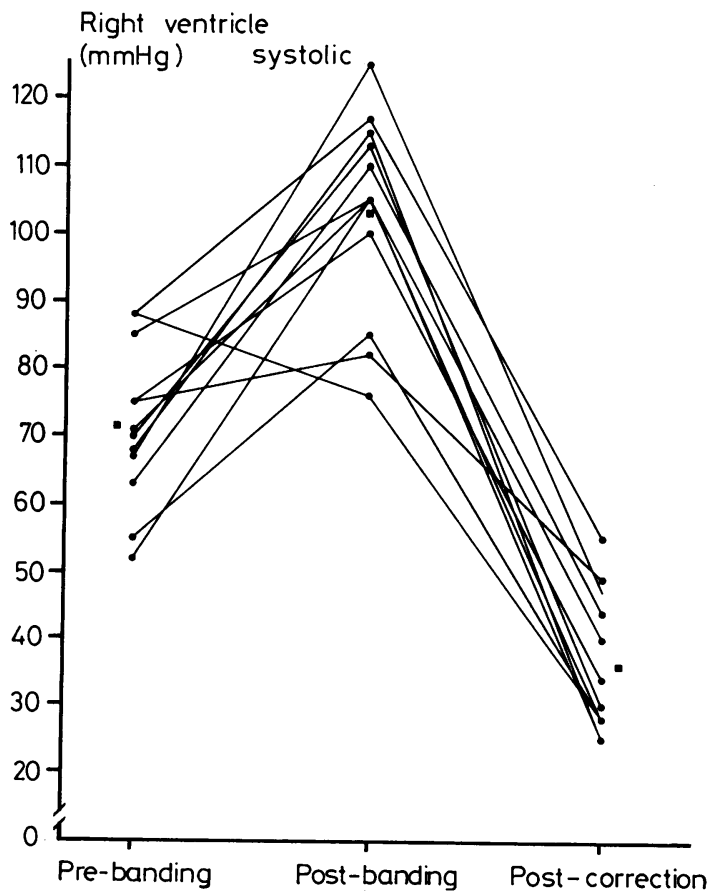

Fig 3 Right ventricular systolic pressure before banding, after banding, and after definitive repair.
Ten patients were asymptomatic after correction. One patient noticed dyspnoea on slight to moderate exercise and another complained of periodic oppression in the chest, not provoked by exercise.

Seven of the patients were maintained on a small dose of digoxin in the early postoperative period after debanding. None of the patients were receiving cardiac drugs before the debanding.

Before debanding the electrocardiogram showed moderate to severe right-sided hypertrophy in ten patients and right bundle-branch block in two. After debanding all patients had right bundlebranch block except for one patient with complete heart block.

Microscopy of the resected infundibular muscle showed myocardial fibrosis and degenerative changes in the myocardial cells. There was severe fibrosis at the site of the pulmonary artery banding and calcium deposits in the arterial wall were found in several cases.

Two patients developed complete heart block after correction, one of whom died.

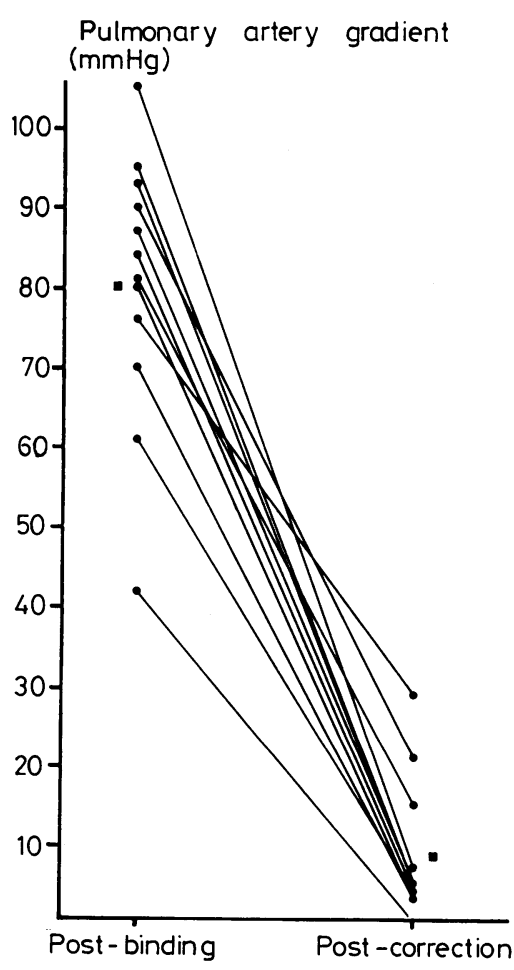

Fig 4 Pulmonary artery gradient after banding and after definitive repair. 


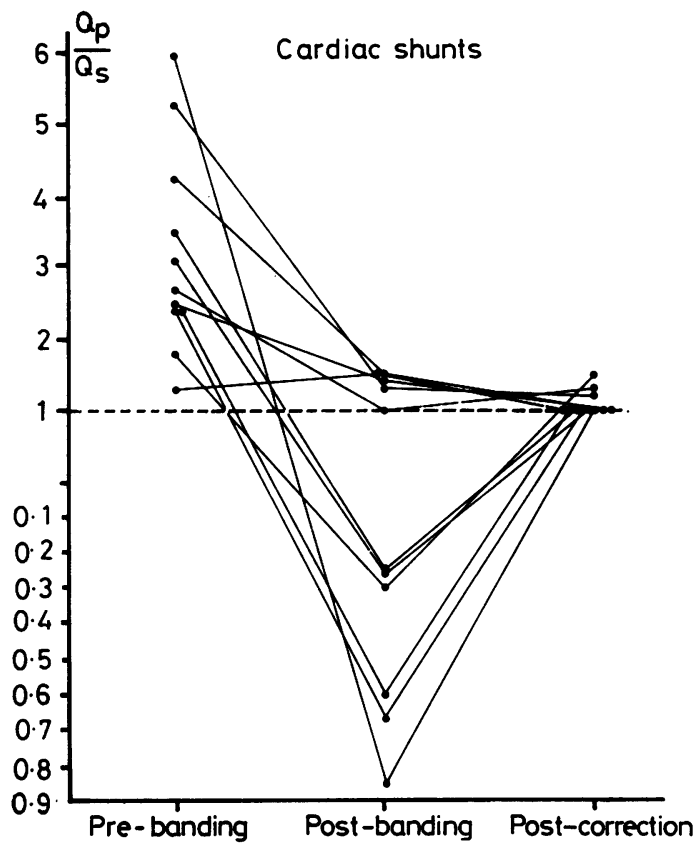

Fig 5 Before banding all patients had arteriovenous shunts. After definitive repair nine patients had no shunt and three had minor arteriovenous shunts.

\section{Necropsy findings}

Two patients died in the immediate postoperative period. The first, a 4-year-old boy, was operated on in June 1974. Surgical heart block resulted, and temporary pacing wires were attached to the right ventricle. He remained in low cardiac output, developed renal failure, and died on the second day. Necropsy showed that the VSD was closed and that there was a wide pulmonary artery at the former banding site. Microscopy showed myocardial hypertrophy, subendocardial bleeding, and necrosis in the septum where the VSD patch was inserted.

The second, a 9-year-old boy, was operated on in October 1976. The band had migrated close to the bifurcation of the pulmonary artery resulting in stenosis of both pulmonary arterial branches. There was also severe fibrosis around the band. It was decided to proceed with excision of the band, but the anastomosis of the main pulmonary artery to the pulmonary artery branches were very difficult, and the bypass time was five hours. After termination of the extracorporeal circulation the right ventricular pressure was at systemic level. The patient died a few hours later from cardiac failure. At necropsy the VSD was closed, and there was some stenosis of the anastomosis be-

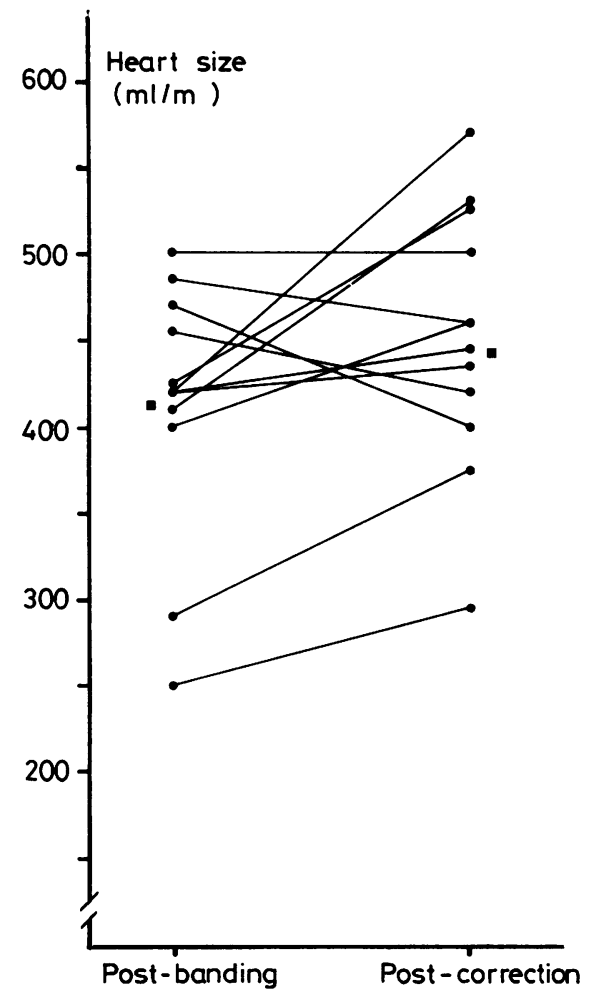

Fig 6 Heart size before definitive repair and at time of follow-up.

tween the main pulmonary artery and the bifurcation.

\section{Discussion}

Banding of the pulmonary artery has been used for palliative treatment of excessive pulmonary 은 blood flow secondary to VSD when it is an isolated lesion or when combined with other malformations, such as transposition of the great vessels, $N$ truncus arteriosus, or coarctation of the aorta (Hunt et al, 1971). The operative mortality has $\tilde{O}$ been about $15 \%$ (Therkelsen et al, 1959; Stark et $\mathbb{\omega}^{N}$ al, 1969; Patel et al, 1973), but in recent years 3\% O (Trusler and Mustard, 1972) in cases with minor 0 associated defects. Despite continued medical $\stackrel{\odot}{\varnothing}$ treatment congestive heart failure and recurrent $\stackrel{\infty}{+}$ pneumonia can still be a problem after pulmonary 0 artery banding (Dobell et al, 1973; Stark et al, $\stackrel{\vec{\Phi}}{\mathbb{Q}}$ 1969; Hunt et al, 1971). This has not been the $\stackrel{\Phi}{\square}$ case in the present group. At the time of definitive $\stackrel{\mathbb{Q}}{\stackrel{Q}{ }}$ intracardiac repair the band presents technical 0 problems as a patch enlargement is often necessary to relieve the stenosis at the band site or the 
branch stenosis resulting from migration of the band to the bifurcation (Hunt et al, 1970). The operative mortality has been about $20 \%$ (Stark et al, 1969; Patel et al, 1973; Kirklin et al, 1976; Seybold-Epting et al, 1976) at the time of definitive repair. Residual systolic gradients across the debanded area of greater than $30 \mathrm{mmHg}$ have been recorded in $30 \%$ of patients (Stark et al, 1969).

Our early experience of debanding was similar and stimulated us to search for a more effective technique for debanding. Since October 1972 we have used the present technique (fig 1) in all cases where the band was still located on the main pulmonary artery.

In cases where the band has migrated peripherally causing fibrous stenosis of the right and left branches complete resection should probably not be performed because this makes the operation difficult, as we found in one of our cases who died. In such cases we have recently preferred patch repair with pericardium or with glutaraldehyde preserved pig pericardium.

In contrast to most other reports, our patients have undergone definitive intracardiac repair and debanding rather late. The mean banding period was $13 \cdot 3$ years (SD $3 \cdot 8$ ). This probably accounted for the presence of secondary muscular hypertrophy necessitating infundibular resection in every case. Hunt et al (1970) found acquired infundibular stenosis in three of their eight patients, but it was of no haemodynamic significance. In their cases the debanding was performed four to eight years (mean five) after banding. They noted thickening of the pulmonary valve cusps resulting in mild valvar stenosis in seven cases.

Small minor left to right shunts persist in three of the surviving patients, one of whom also has tricuspid incompetence and cardiomegaly. A major increase in heart size after repair suggests that there is some additional cardiac disease.

Our cases show that patients banded in infancy can develop almost normally and tolerate a severe degree of artificial supravalvar stenosis, which does not change in size and which does not interfere with normal development of the pulmonary valves.

From our results we conclude that debanding by excision of the banded segment can be performed with no significant residual pulmonary gradient and is a satisfactory method when the banding period has been unusually long. This method should be reserved for cases where the band is located in the middle of the main pulmonary artery.

Our present policy is to undertake primary repair of isolated VSDs. We reserve banding for patients with VSDs and complicating cardiac disease, and proceed to debanding and definitive repair two years later. At this age excision of the band site is usually unnecessary as the pulmonary artery can be dilated after removal of the band.

\section{References}

Dobell, A R C, Murphy, D A, Poirier, N L, and Gibbons, J E (1973). The pulmonary artery after debanding. Journal of Thoracic and Cardiovascular Surgery, 65, 32-36.

Hunt, C E, Formanek, G, Castaneda, A, and Moller, J H (1970). Closure of ventricular septal defect and removal of pulmonary arterial band. American Journal of Cardiology, 26, 345-350.

Hunt, C E, Formanek, G, Levine, M A, Castaneda, A, and Moller, J H (1971). Banding of the pulmonary artery: results in 111 children. Circulation, 43, 395-406.

Jonsell, S (1939). A method for the determination of the heart size by teleroentgenography. (A Heart Volume Index). Acta Radiologica, 20, 325-339.

Kirklin, J W, Appelbaum, A, and Bargeron, L M (1976). Primary repair versus banding for ventricular septal defects in infants. In The Child with Congenital Heart Disease after Surgery, edited by B S L Kidd, and R D Rowe, pp 3-9. Futura, New York.

Muller, W H, and Dammann, J F (1952). The treatment of certain congenital malformations of the heart by the creation of pulmonic stenosis to reduce pulmonary hypertension and excessive pulmonary blood flow. Surgery, Gynecology and Obstetrics, 95, 213-219.

Patel, R G, Ihenacho, H N C, Abrams, L D, Astley, R, Parsons, C G, Roberts, K D, and Singh, S P (1973). Pulmonary artery banding and subsequent repair in ventricular septal defect. British Heart Journal, 35, 651-656.

Seybold-Epting, W, Reul, G J, Hallman, G L, and Cooley, D A (1976). Repair of ventricular septal defect after pulmonary artery banding. Journal of Thoracic and Cardiovascular Surgery, 71, 392-397.

Stark, J, Aberdeen, E, Waterston, D J, Bonham-Carter, R E, and Tynan, M (1969). Pulmonary artery constriction (banding): A report of 146 cases. Surgery, 65, 808-818.

Therkelsen, F, Gammelgaard, P A, and Boesen, I (1959). Ventricular septal defects in infants treated with various modifications of the Dammann-Muller operation. Acta Chirurgica Scandinavica, suppl, 245, 249-258.

Therkelsen, F (1968). Congenital cardiac diseases in infants. Diseases of the Chest, 53, 528-533.

Trusler, G A, and Mustard, W T (1972). A method of banding the pulmonary artery for large isolated ventricular septal defect with and without transposition of the great arteries. Annals of Thoracic Surgery, 13, 351-355.

Requests for reprints to: Dr P Lauridsen, Department of Thoracic Surgery, Rigshospitalet, Copenhagen. 